\title{
Особенности представлений подростков о правах ребенка
}

\author{
Анна В. Черная, Людмила Н. Гришина* \\ Южный федеральный университет, г. Ростов-на-Дону, Российская Федерация \\ *E-mail: Ingrishina@sfedu.ru
}

\begin{abstract}
Аннотация
Ввеление. В предметном поле исследований прав ребенка актуализировано еАинство внешнего и внутреннего - и как внешней социальной среАы, с которой взаимодействует субъект, и как внутренней реальности самого субъекта прав, обеспечивающей самореализацию, автономию, своболу; показана сопряженность исследовательской проблематики по правам ребенка с вопросами Аетского благополучия и образования в сорере прав человека/ребенка. Приведены Аанные об использовании метолов исследования представлений о правах ребенка, раскрыты принципы участия Аетей в исслеАовании их прав, особенности Аиагностического инструментария. Представлены результаты эмпирического исследования преАставлений подростков 10-15 ^ет о правах ребенка.
\end{abstract}

Методы. В исслеАовании использовался экспресс-опросник «ПреАставления о правах ребенка», основанный на принципах построения и солержания ФлешЕвробарометра ЕС «Конвенция о правах ребенка» и анкеты ЮНИСЕФ «Аетский игровой отчет по правам ребенка».

Результаты. В холе исследования получены Аанные об особенностях представлений подростков о правах ребенка, о возрастных различиях в представлениях полростков о правах ребенка. Различия в представлениях полростков о правах ребенка 10-11 и 14-15 лет связаны с большей освеАомленностью 14-15-летних полростков о правах ребенка, осознанием их важности и значимости, невозможности их ограничения, предпочтениями относительно источников получения инорормации о правах ребенка.

ОбсужАение результатов. Новизна исследования заключается в разработке и использовании экспресс-опросника «Представления о правах ребенка», в по^ученных $А$ анных о возрастных особенностях представлений о правах ребенка. Результаты эмпирического исслеАования представлений о правах ребенка в поАростковом возрасте могут быть использованы при проектировании программ психологического просвещения и образования подростков в сорере прав ребенка. Результаты исследования показывают перспективность Аанного направления в профрессиональной Аеятельности пеАагогов-психологов. 


\title{
КАючевые слова
}

психология развития, права человека, права ребенка, представления о правах ребенка, подростковый возраст, методы исследования, образование по правам ребенка, психологическое просвещение, Аетское развитие, Аетское благополучие

\section{Основные положения}

- особенности представлений о правах ребенка в полростковом возрасте отражают обобщенный социальный опыт подростков О важности и значимости

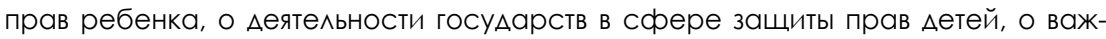
ности специального обучения по правам ребенка и информирования о правах ребенка в СМИ;

- возрастные различия в представлениях о правах ребенка полростков 10-11, 12-13, 14-15 ^ет связаны с Аоминирующими в кажАом возрасте тенденциями, раскрывающими составляющие социального опыта поАростков;

- характер представлений полростков о правах ребенка может быть использован при проектировании программ психологического просвещения и образования Аетей и полростков в сорере прав ребенка.

\section{Для цитирования}

Черная А.В., Гришина Л.Н. Особенности представлений подростков о правах ребенка // Российский психологический журнал. 2018. Т. 15, № 2. С. 60-82. DOI: 10.21702/rpj.2018.2.3

Материалы статьи получены 12.10.2017

UDC 159.9.072

DOI: $10.21702 /$ rpj.2018.2.3

\section{Adolescents' Notions of Children's Rights}

\section{Anna V. Chernaya, Lyudmila N. Grishina*}

Southern Federal University, Rostov-on-Don, Russian Federation

*Corresponding author. E-mail: Ingrishina@sfedu.ru

\begin{abstract}
Introduction. Research on children's rights is helping unify the external social environment with which the subject interacts and the subject's internal reality, which is a foundation for self-realization, autonomy, and freedom. This paper: (a) describes the interrelationships among the problems in studying children's rights and the issues of child welfare and education in the field of human/children's rights; (b) concentrates on methods for studying notions of children's rights; (c) considers the principles of children's participation in the
\end{abstract}


study of their rights; (d) presents relevant diagnostic tools; and (e) reports the results of an empirical study on notions of children's rights among adolescents aged 10-15 years.

Methods. The study employed the Rapid Survey on Notions of Children's Rights which followed the principles and logic of the Flash Eurobarometer: The Rights of the Child and the Children's Report on Child Rights and Children's Issues by UNICEF.

Results. The study discovered age-related differences in notions of children's rights among adolescents. Adolescents aged 14-15 years were characterized by greater awareness of the rights of the child than that of their 10-11-year-old counterparts. This difference was based on higher levels of comprehension of children's rights, the awareness of their importance and the impossibility of their restriction, and on preferences for the sources of information on children's rights.

Discussion. The newly developed diagnostic tool, the Rapid Survey on Notions About Children's Rights, was used to collect data on age differences in notions about children's rights. The study results can be readily used in developing programs for the psychological education of adolescents in the field of children's rights. This line of research has great potential for the professional activities of educational psychologist.

\section{Keywords}

developmental psychology, human rights, children's rights, notions of children's rights, adolescence, research methods, education in children's rights, psychological education, child development, child welfare

\section{Highlights}

Adolescents' notions of children's rights reflect their generalized social experience concerning: (a) the importance of the rights of the child; (b) specific governments actions in protecting children's rights; and (c) special education and information on the rights of the child in mass media.

- Adolescents from different age groups (i.e., 10-11, 12-13, and 14-15 years old) have different dominant tendencies in unfolding social experiences, which in turn, determine age-related differences in notions of children's rights.

- Understanding adolescents' notions of children's rights can be useful for developing programs for the psychological education of children and adolescents in the field of children's rights.

\section{For citation}

Chernaya A.V., Grishina L. N. Adolescents' Notions of Children's Rights. Rossiiskii psikhologicheskii zhurnal - Russian Psychological Journal, 2018, V. 15, no. 2, pp. 60-82 (in Russian). DOI: 10.21702/rpj.2018.2.3 


\section{Введение}

\section{Исследования представлений о правах ребенка}

За последние десятилетия категория прав человека усилила свое влияние на многие социальные проблемы, включая развитие и образование. Обсуждение прав ребенка приобрело значительный масштаб после принятия Конвенции о правах ребенка (1989 г.), признавшей правовой статус детей как субъектов права, наделенных от рождения до достижения ими восемнадцатилетнего возраста всей совокупностью прав и свобод человека. В сложившуюся систему взглядов на детство и детское развитие, благодаря Конвенции о правах ребенка, был включен антропоцентрический термин «права ребенка» (The Rights of the Child), фокусирующий внимание исследователей на жизни детей, поддержке их развития и выживания.

В рамках исследования представлений подростков о правах ребенка решались две группы задач: теоретические и эмпирические. Систематизация исследований о правах ребенка в работах отечественных и зарубежных авторов, о международных инициативах по изучению представлений о правах ребенка, и анализ качественного своеобразия методов исследования прав ребенка послужили основанием для апробации авторского экспрессопросника диагностики представлений о правах ребенка, используемого в эмпирическом исследовании.

Интерес к исследованию прав ребенка в психологии сопряжен с социально-психологическим анализом включенности личности в систему обязанностей и прав, которая рассматривается как условие обретения ею ключевых позиций для жизненных ориентаций и индивидуальных смыслов. Поле прав человека исследуется психологами с точки зрения единства внешнего и внутреннего - и как социальная среда, с которой взаимодействует субъект, и как внутренняя реальность субъекта, обеспечивающая возможности для самореализации, автономии, свободы взаимодействия с Другими на основе уважения и признания их прав. Согласно В.С. Мухиной, принадлежность человека к существующей системе обязанностей и прав в государственной структуре, в которой осуществляются его права и свободы, обеспечивает его потребность быть уникальной личностью, испытывать чувство защищенности. В.С. Мухина полагает, что общество, отводя детям определенное значение в социальном пространстве взрослых и сверстников, вырабатывает систему особых требований к детям, круг их прав и обязанностей, которые имеют важнейшее значение в формировании личности. Социальное пространство личности - условие развития и бытия человека, которое психологически вводит его в сферу прав и обязанностей. Ребенку, для того чтобы понять права и обязанности, требуется помощь посредника, и лишь в подростковом возрасте формирующаяся личность предпринимает 
попытку осознать значения и смыслы прав и обязанностей, притязая на определенные права [1].

K. Daiute указывает на необходимость анализа прав ребенка, представленных в Конвенции о правах ребенка в контексте идеи взаимодействия человека и общества и социокультурной теории развития Л.С. Выготского, А.Н. Леонтьева. Автор полагает, что анализируя развитие ребенка как социально-культурно-политический процесс, а не как процесс созревания или социализации, мы можем лучше выявлять проблемы и определять условия развития, включая сложные ситуации, которые бросают вызов правам детей, что, в свою очередь, позволяет улучшить социально-политические аспекты детского развития, особенно в отношении прав детей и возможностей для их самоопределения [2].

В работах зарубежных авторов также актуализируются вопросы социальной и личностной автономии ребенка, подкрепленные их правами, вклад прав ребенка в развитие детей и детское благополучие. D. Tarulli, H. Skott-Myhre подчеркивают, что современные дети и подростки как субъекты права, чувствительные к социальным и историческим переменам, к текущим событиям, отличаются такими личностными характеристиками, как автономность, открытость, способность добровольно высказывать свою позицию и быть включенными в принятие решений [3]. L. Krappmann считает важным рассматривать ребенка как человека, имеющего право на уважение, как уникальную личность с ее собственной точкой зрения и личными намерениями со стороны людей, государства и других организаций [4]. M. Liebel акцентирует привлекательность прав для самих детей, связанную с возможностью реализации детьми своих прав в различных социальных и культурных контекстах [5]. A. Ben-Arieh, I. Frønes указывают на то, что предоставляемые государствами гарантии для реализации и обеспечения прав ребенка выступают индикаторами детского благополучия. При таком подходе акцентируется позиция включенности, активности ребенка как субъекта права [6].

Перечисленные подходы к исследованию прав ребенка встроены в более широкий контекст понимания детства и детского развития, ключевые идеи которого складывались на протяжении двадцатого столетия в науках о детстве, социальном статусе детства и положении детей и были связаны с образом детей как развивающихся взрослых [7], постепенно трансформировавшимся в образ детей как активных участников в построении собственной жизни, жизни своей семьи и общества, а также как носителей прав человека [8].

В обобщенном виде данная идея представлена в работах N. Peleg. Автор полагает, что активность ребенка в реализации его права на развитие означает не только право на то, чтобы стать свободным взрослым, но и право быть свободным ребенком, становясь свободным взрослым [9]. 
Следует отметить вклад Конвенции о правах ребенка в формирование отношения к детству и детскому развитию, включенных в более широкий социальный контекст «статус / положение детей» (State of the Child), в настоящее время использующийся для комплексной оценки качества жизни и здоровья детей, детского благополучия, в том числе и прав ребенка [10].

Важным аспектом в психологических исследованиях прав ребенка, фокусирующем внимание исследователей на активности ребенка и возможностях освоения совокупности прав, участии в образовании в области прав человека, является изучение представлений детей о правах ребенка. Рассмотрение представлений ребенка о своих правах и обязанностях делает приоритетной задачу исследования данной категории в подростковом возрасте, в рамках которого становится возможной рефлексия совокупности социальных и личностных прав и свобод. Согласно взглядам Л. С. Выготского, подростковый возраст характеризуется особым строением сознания. Самосознание как социальное сознание, перенесенное внутрь, является совместным знанием в системе отношений; самосознание - это общественное знание, перенесенное во внутренний план мышления [11]. Данная идея Л.С. Выготского определена нами как методологический базис в исследовании представлений подростков о правах ребенка, рефлексирующих социальный опыт своих прав и обязанностей.

Учитывая актуальность категории «права ребенка» и ее значимость для подросткового возраста, нами проведено исследование, цель которого - изучить особенности представлений о правах ребенка в подростковом возрасте.

\section{Международные проекты по изучению представлений о правах ребенка}

Связанная с правами работа специалистов, заинтересованных в развитии и воспитании детей, работающих с детьми, получила исследовательский импульс, начиная с середины 1980-х гг., путем начала изучения перспектив детей и взрослых по вопросам важности и наличия прав детей. Около 40 лет Международная ассоциация школьной психологии (ISPA), целевая группа которой выделила в качестве своих приоритетов вопросы детского благополучия и права ребенка, инициирует проекты по защите прав детей, поддержке развития и образования детей, обеспечению безопасности детей [12].

В «Международном обзоре детского благополучия», - уникальном исследовании, проведенном под руководством A. Ben-Arieh, изучены взгляды детей на их субъективное благополучие, особенности восприятия и знаний своих прав, а также самоотчеты о реализации права на участие. В исследовании, проведенном на выборке более 54000 детей в возрасте 8-12 лет из 16 стран 
мира, показаны различия между знаниями детей о правах и восприятием их прав, и их отчетами об участии. Результаты исследования свидетельствуют о том, что право детей на участие и, в определенной степени, их знания и понимание их прав являются показателями их субъективного благополучия [13].

В целевых приоритетах деятельности Европейской федерации ассоциаций психологов (EFPA) с 2014 г. инициированы проекты поощрения и поддержки образования в области прав человека для психологов. Примеры лучших психологических практик связаны: с поощрением и защитой прав детей в целях содействия детскому благополучию; с разработкой инструментов, помогающих детям научиться понимать свои права и определять, что является неприемлемым поведением в сфере прав человека; с обучением сотрудников образовательных организаций и правоохранительных органов методам выявления детей, подвергшихся риску нарушений их прав. Как средство достижения результатов в поддержке прав ребенка, его развития как личности и социального существа, включенного в культурный контекст, рассматривается формирование культуры прав ребенка у психологов, родителей и более широкого социального окружения [14].

\section{Методы исследования представлений о правах ребенка}

Использование количественных и качественных методов, связанных с изучением прав ребенка, базируется на традиционных для психологии развития подходах, связанных с превалированием сугубо детских методов и стратегий исследования детского развития. Социокультурный подход к детскому участию, включенности детей как исследователей связан с поиском эффективных стратегий «слушания» детских голосов и позицией взрослых исследователей, которые, адекватно информируя потенциальных участников, получают уникальную возможность изучать новые способы общения с детьми [15]. Выбор методов исследования прав детей основывается на универсальных правах человека и правах ребенка, которые приветствуют участие заинтересованных сторон, включая детей [16], на соблюдении основных принципов Конвенции о правах ребенка: права на участие и права на защиту [17]. Согласно B. Nastasi, исследования, связанные с уважением прав, требуют использования методов, которые могут «охватывать взгляды или опыт детей в их собственных высказываниях, облегчать их общение со взрослыми, обеспечивать возможность участия детей в принятии решений, содействие участия ребенка в качестве со-исследователя со взрослыми. В идеале дети как ключевая заинтересованная сторона должны участвовать во всем исследовательском процессе: в определении целей исследования, принятии решений о сборе данных, в сборе данных, анализе, интерпретации результатов исследований» [18, с. 326]. 


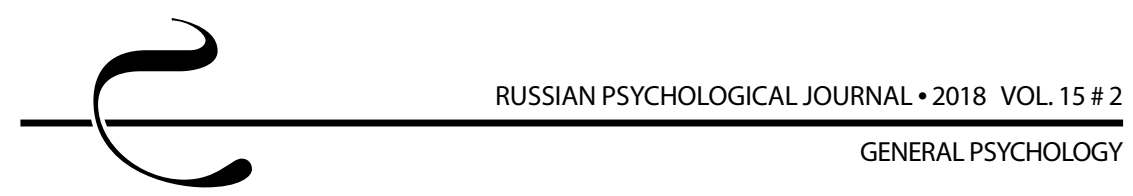

Ряд авторов подчеркивают важность: личного участия детей в изучении представлений об их правах; обязательного учета их мнений; партнерского участия ребенка в исследовании, в ходе которого дети, вне зависимости от возраста, имеют право быть выслушанными; улучшения качества взаимоотношений между исследователем и детьми, создания благоприятного психологического климата в группе исследуемых детей [19, 20, 21, 22].

Согласно E. Backe-Hansen, специалистам, проводящим исследования с детьми и подростками на основе партнерства, удается избежать ряда проблем: уязвимости детей в ходе исследования; неточности в интерпретации используемых детьми понятий; принуждения ребенка к участию в исследовании [17].

Диагностический инструментарий, представленный в международной практике, ориентирован: на изучение представлений о правах ребенка (ФлешЕвробарометр EC «Конвенция о правах ребенка») [23, 24]; на оценку уровня осведомленности о своих правах (опрос ЕС «Права ребенка глазами детей») [25]; на выявление представлений о праве на образование, об отношении к употреблению психоактивных веществ и наркотиков, и к правам детей с ограниченными возможностями здоровья (анкета ЮНИСЕФ «Детский игровой отчет по правам ребенка») [26]; на изучение мнений детей о праве на выживание, защиту, участие и развитие (интервью «Детский отчет о своих правах (Бихар)» [27].

Арсенал методов, рекомендуемых профессиональными ассоциациями (Ассоциация социальных исследований, Ассоциация социальных антропологов Содружества, Британская социологическая ассоциация, Британская психологическая ассоциация) в исследованиях представлений о правах ребенка, включает визуальные, письменные, устные, рисуночные, игровые методы [28].

На этапе исследования особенностей представлений о правах ребенка подростков 10-15 лет решались следующие эмпирические задачи: изучить особенности представлений подростков о правах ребенка с помощью экспресс-опросника «Представления о правах ребенка» на выборке подростков 10-11, 12-13, 14-15 лет; провести количественный и качественный анализ данных о представлениях подростков о правах ребенка. Гипотеза исследования состояла в предположении о том, что представления о правах ребенка в подростковом возрасте отражают обобщенный социальный опыт подростков о важности и значимости прав ребенка, о деятельности государств в сфере защиты прав детей, о важности специального обучения по правам ребенка и информирования о правах ребенка в СМИ. Мы также предположили, что существуют возрастные различия в представлениях о правах ребенка подростков 10-11, 12-13, 14-15 лет. 
ОБЩАЯ ПСИХОЛОГИЯ

В эмпирическом исследовании, проведенном в 2014-2016 гг., приняли участие 125 подростков 10-15 лет, обучающихся в образовательных организациях г. Ростова-на-Дону - МБОУ «Лицей № 103 им. С. Козлова», МАОУ «Школа № 96 Эврика-Развитие им. М. Нагибина».

\section{Методы}

В исследовании использовался адаптированный авторами экспрессопросник «Представления о правах ребенка» (таблица 1).

Таблица 1. Экспресс-опросник «Представления о правах ребенка»

Table 1. Rapid Survey on Notions About Children's Rights

В Аанном опроснике слово «ребенок» понимается, согласно определению Организации Объединенных Наций, как ^ицо, не Аостигшее 18 ^ет. - Прим. авт.

\begin{tabular}{|c|c|}
\hline \multicolumn{2}{|c|}{ Инструкция } \\
\hline $\begin{array}{l}\text { Аля сбора инорормации с целью изу- } \\
\text { чения твоих прелставлений о правах } \\
\text { ребенка, в приведенных ниже вопро- } \\
\text { сах или утвержлениях поставь } \checkmark \text { перед } \\
\text { выбранным вариантом ответа }\end{array}$ & 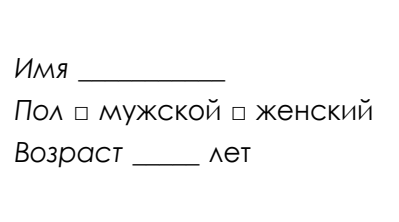 \\
\hline Вопросы & Варианты ответов \\
\hline $\begin{array}{l}\text { 1. Знаешь ^и ты что-нибуль о правах } \\
\text { ребенка? }\end{array}$ & $\begin{array}{l}\square \text { Аа, знаю } \\
\square \text { нет, не знаю } \\
\square \text { затрудняюсь ответить }\end{array}$ \\
\hline $\begin{array}{l}\text { 2. Считаешь ми ты необходимым учи- } \\
\text { тывать интересы детей при принятии } \\
\text { государственных законов? }\end{array}$ & $\begin{array}{l}\square \text { Аа } \\
\square \text { нет } \\
\square \text { затрудняюсь ответить }\end{array}$ \\
\hline $\begin{array}{l}\text { 3. Знаешь ми ты, что дети имеют осо- } \\
\text { бые, по сравнению со взрослыми, } \\
\text { права? }\end{array}$ & $\begin{array}{l}\square \text { Аа } \\
\square \text { нет } \\
\square \text { затрудняюсь ответить }\end{array}$ \\
\hline
\end{tabular}




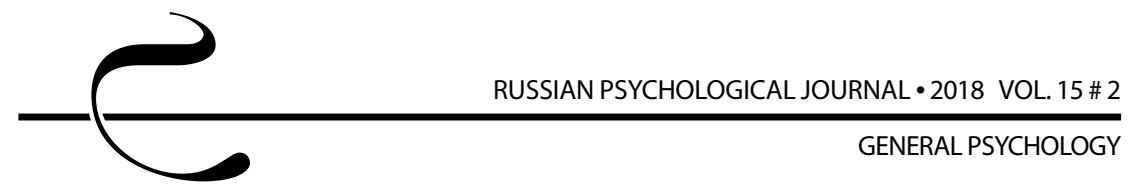

\begin{tabular}{|c|c|}
\hline $\begin{array}{l}\text { 4. Считаешь ^и ты важными для ребен- } \\
\text { ка права на: защиту и заботу; свобол- } \\
\text { ное выражение своего мнения; доступ } \\
\text { к инорормации; отдых и досуг? }\end{array}$ & $\begin{array}{l}\square \text { Аа } \\
\square \text { нет } \\
\square \text { затрудняюсь ответить }\end{array}$ \\
\hline $\begin{array}{l}\text { 5. Считаешь ^и ты, что твои права пол- } \\
\text { ностью защищены? }\end{array}$ & $\begin{array}{l}\square \text { Аа } \\
\square \text { нет } \\
\square \text { затрудняюсь ответить }\end{array}$ \\
\hline $\begin{array}{l}\text { 6. Как ты считаешь, Аопустимо ^и огра- } \\
\text { ничение твоих прав? }\end{array}$ & $\begin{array}{l}\square \text { Аа } \\
\square \text { нет } \\
\square \text { затрудняюсь ответить }\end{array}$ \\
\hline $\begin{array}{l}\text { 7. Считаешь ми ты, что Аети могут стол- } \\
\text { кнуться с проблемами, когАа им по- } \\
\text { надобится помощь по защите своих } \\
\text { прав? }\end{array}$ & $\begin{array}{l}\square \text { Аа } \\
\square \text { нет } \\
\square \text { затрудняюсь ответить }\end{array}$ \\
\hline $\begin{array}{l}\text { 8. Считаешь ^и ты важным специально } \\
\text { организованное обучение по правам } \\
\text { ребенка? }\end{array}$ & $\begin{array}{l}\square \text { Аа } \\
\square \text { нет } \\
\square \text { затрудняюсь ответить }\end{array}$ \\
\hline $\begin{array}{l}\text { 9. Важна ^и Аля тебя инфоормация } \\
\text { о правах ребенка в СМИ? }\end{array}$ & $\begin{array}{l}\square \text { Аа } \\
\square \text { нет } \\
\square \text { затрудняюсь ответить }\end{array}$ \\
\hline \multicolumn{2}{|c|}{ Благодарим за участие! } \\
\hline
\end{tabular}

В основу опросника положены принципы построения и содержание вопросов Флеш-Евробарометра ЕС «Конвенция о правах ребенка» $[23,24]$ и анкеты ЮНИСЕФ «Детский игровой отчет по правам ребенка» [26]. Экспрессопросник направлен на выявление представлений подростков о ситуациях и событиях, связанных с правами ребенка. Опросник ориентирован на сбор Q-данных (от «question» - вопрос), включающих самоотчеты или ответы на вопросы, полученные непосредственно от респондентов [29]. 
В опроснике использована закрытая форма вопросов, предусматривающая три варианта ответа: «да», «нет», «затрудняюсь ответить». Вопросы опросника мы сгруппировали в три блока. В первый блок включены вопросы о важности и значимости прав ребенка и их отличии от прав взрослых. Во второй блок - вопросы о деятельности государств в сфере защиты прав детей. В третий блок - вопросы о важности специально организованного обучения и информирования о правах ребенка в СМИ. Вопросы о правах ребенка соответствуют статьям Конвенции о правах ребенка: статьям 16, 19, 29, 22, 38, $39,32,33,34,36,30$, отражающим право на защиту и заботу; статьям 12, 13 , отражающим право на свободное выражение своего мнения; статье 31, отражающей право на отдых и досуг; статьям 28, 29, отражающим право на образование; статьям 6, 23, 24, 18, отражающим право на медицинское обслуживание; статье 17, отражающей право на доступ к информации. Данные о представлениях подростков трех возрастных групп по трем блокам вопросов представлены в следующем разделе.

\section{Результаты}

Данные о представлениях 10-11-летних подростков о правах ребенка по каждому из 9-ти вопросов отражены на рисунке 1.

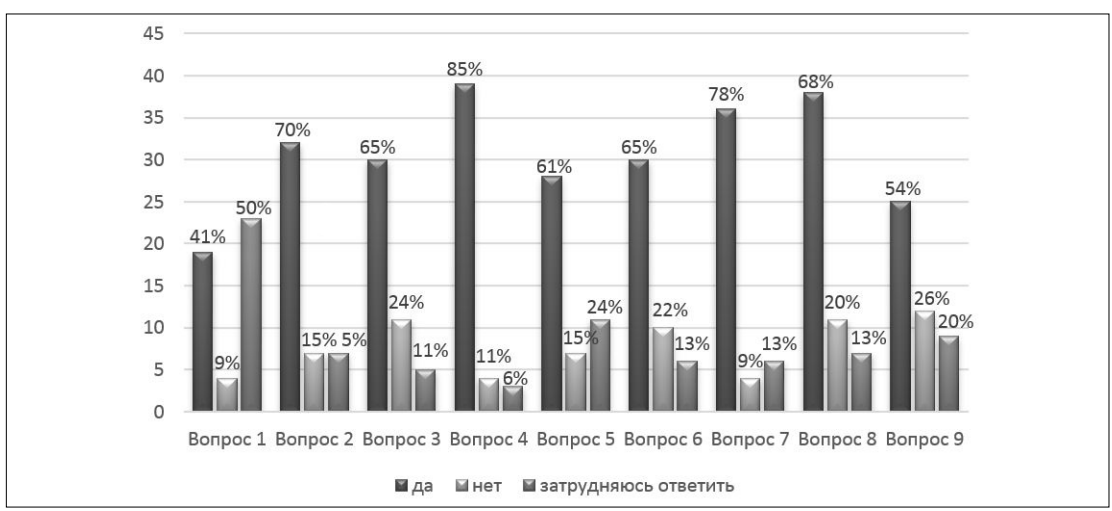

Рисунок 1. Аанные о представлениях подростков 10-11 лет о правах ребенка

Figure 1. Notions about children's rights among adolescents aged 10-11 years

Для 10-11-летних подростков особенно важными (85\% опрошенных) являются: наличие прав на защиту и заботу, свободное выражение своего мнения, доступ к информации, отдых и досуг; $65 \%$ опрошенных считают, что ограничение прав ребенка допустимо. Представления о деятельности государств в сфере обеспечения и защиты прав ребенка неоднозначны. Несмотря 


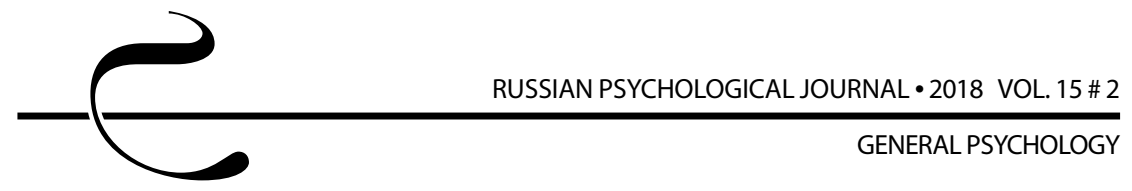

на то, что подростки считают необходимым учитывать интересы детей при принятии государственных законов, и что права ребенка полностью защищены, 78\% подростков полагают, что в ситуации, когда детям понадобится помощь по защите их прав, они могут столкнуться с проблемами. Для $68 \%$ опрошенных подростков представляется важным специально организованное обучение в области прав ребенка.

Данные о представлениях 12-13-летних подростков о правах ребенка по каждому из 9-ти вопросов отражены на рисунке 2.

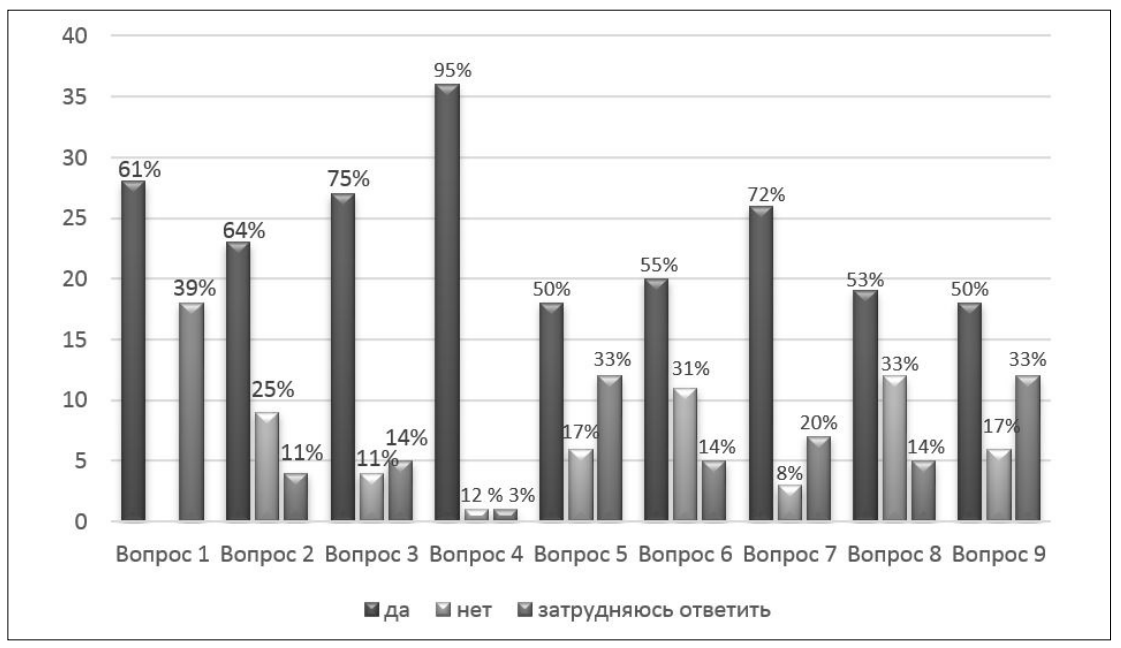

Рисунок 2. Аанные о представлениях подростков 12-13 ^ет о правах ребенка

Figure 2. Notions about children's rights among adolescents aged 12-13 years

Для $95 \%$ 12-13-летних подростков важным является наличие прав у ребенка на защиту и заботу, свободное выражение своего мнения, доступ к информации, отдых и досуг; $55 \%$ опрошенных подростков считают, что ограничение прав ребенка допустимо. Представления о деятельности государств в сфере прав ребенка сходны с представлениями в группе 10-11-летних подростков. Права ребенка, по мнению 12-13-летних подростков, полностью защищены; $72 \%$ подростков считают, что если детям понадобится помощь по защите их прав, они могут столкнуться с проблемами. Для $60 \%$ 12-13-летних подростков представляется в большей степени важным наличие информации о правах ребенка в СМИ, в то время как 10-11-летние подростки более ориентированы на специально организованное обучение в области прав ребенка. 
ОБЩАЯ ПСИХОЛОГИЯ

Данные о представлениях 14-15-летних подростков о правах ребенка по каждому из 9-ти вопросов отражены на рисунке 3.

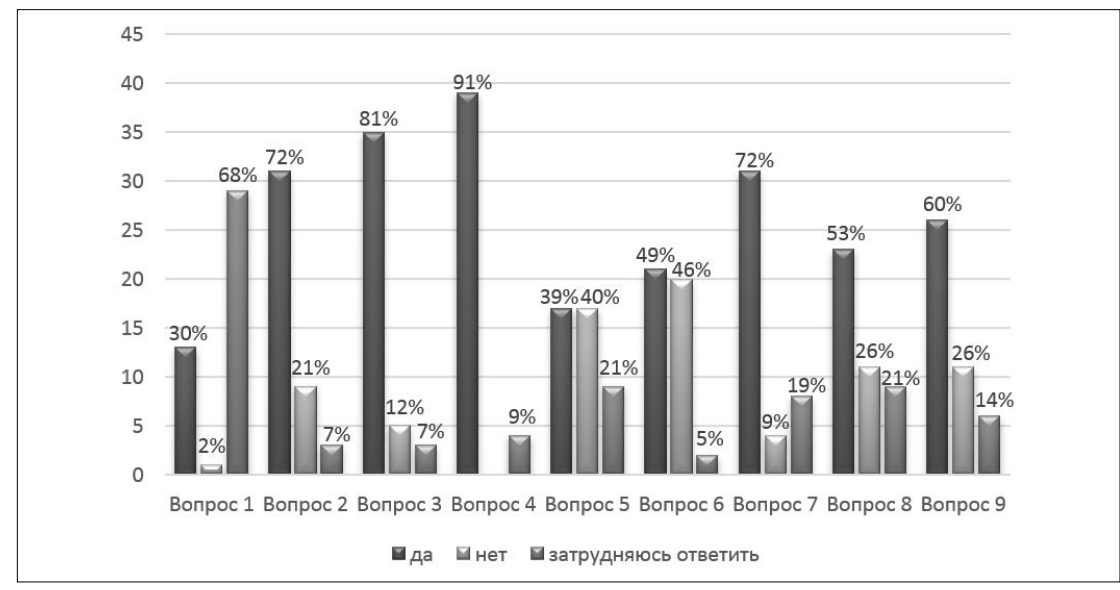

Рисунок 3. Аанные о представлениях подростков 14-15 лет о правах ребенка

Figure 3. Notions about children's rights among adolescents aged 14-15 years

Для 14-15-летних подростков особенно важным (91\% опрошенных) является наличие прав у ребенка на: защиту и заботу; свободное выражение своего мнения; доступ к информации; отдых и досуг. $46 \%$ опрошенных считают, что ограничение их прав недопустимо, и 49\% - что ограничения допустимы. Представления о деятельности государств в сфере прав ребенка отличны от представлений 10-11-летних и 12-13-летних подростков: 78\% опрошенных считают необходимым учитывать интересы детей при принятии государственных законов и отмечают, что права ребенка полностью не защищены (40\%), а также полагают, что в ситуации, когда детям понадобится помощь по защите их прав, они могут столкнуться с проблемами (72\%). Для $60 \%$ 14-15-летних подростков представляется в большей степени важным наличие информации о правах ребенка в СМИ, так же, как и для 12-13-летних подростков.

Далее проводился сравнительный анализ данных об особенностях представлений подростков о правах ребенка, полученных в трех возрастных группах (10-11; 12-13; 14-15 лет). Данные сравнивались по трем блокам вопросов: 1) вопросы о важности и значимости прав ребенка и их отличии от прав взрослых $(1,3,4,6) ; 2)$ вопросы о деятельности государств в сфере защиты прав детей $(2,5,7) ; 3)$ вопросы о важности специально организованного обучения и информирования о правах ребенка в СМИ $(8,9)$. 
Данные по первому блоку вопросов отражены на рисунке 4.

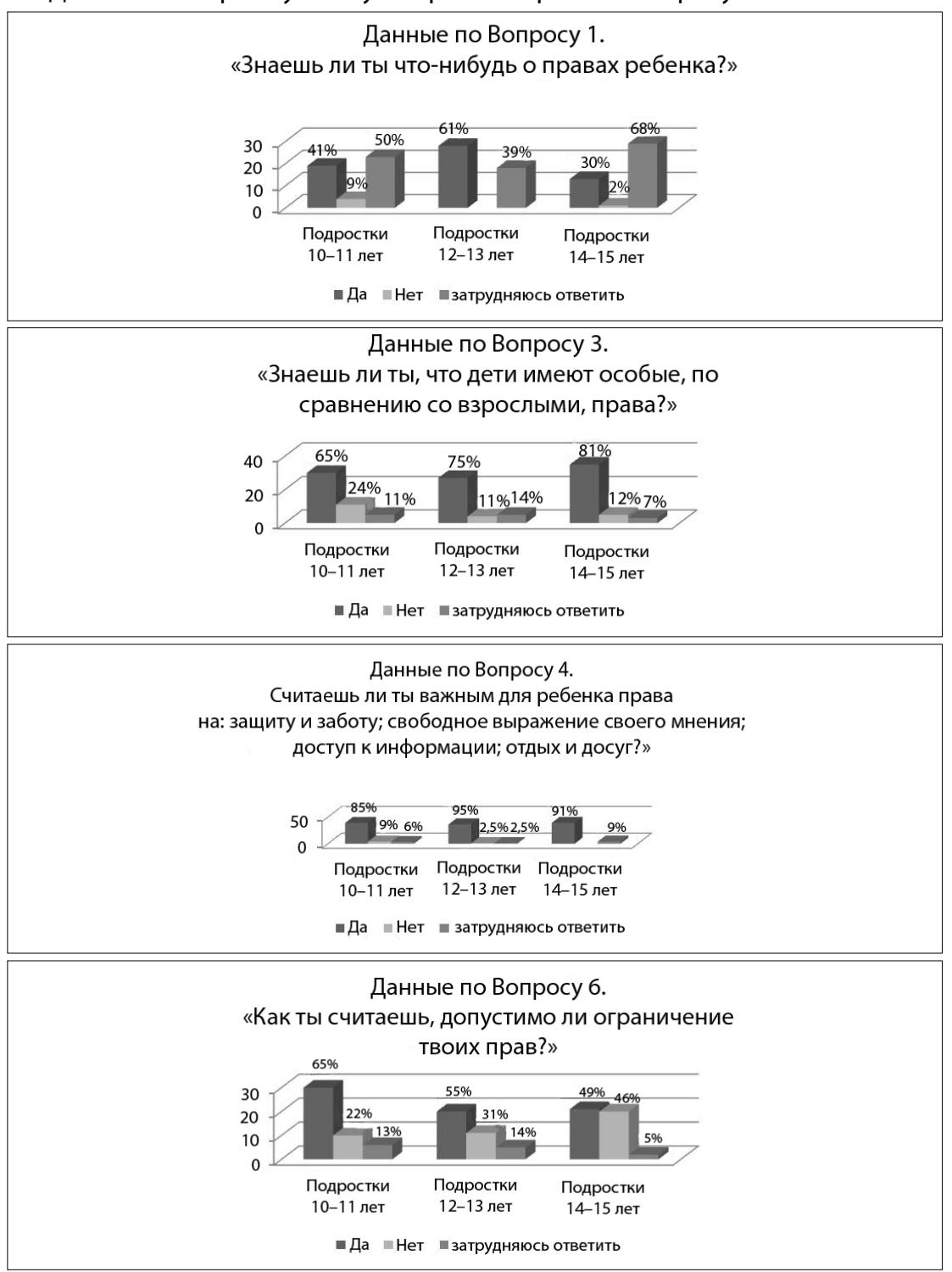

Рисунок 4. Аанные по первому блоку вопросов $(1,3,4,6)$

Figure 4. Data on the first set of questions $(1,3,4,6)$ 
ОБЩАЯ ПСИХОЛОГИЯ

Сравнительный анализ данных о представлениях подростков по первому блоку вопросов в трех возрастных группах показал, что для подростков 14-15 лет особенно важными являются наличие прав у ребенка на защиту и заботу, свободное выражение своего мнения, доступ к информации, отдых и досуг. 65\% подростков 10-11 и 55\% подростков 12-13 лет считают, что ограничение прав ребенка допустимо.

Данные по второму блоку вопросов отражены на рисунке 5.

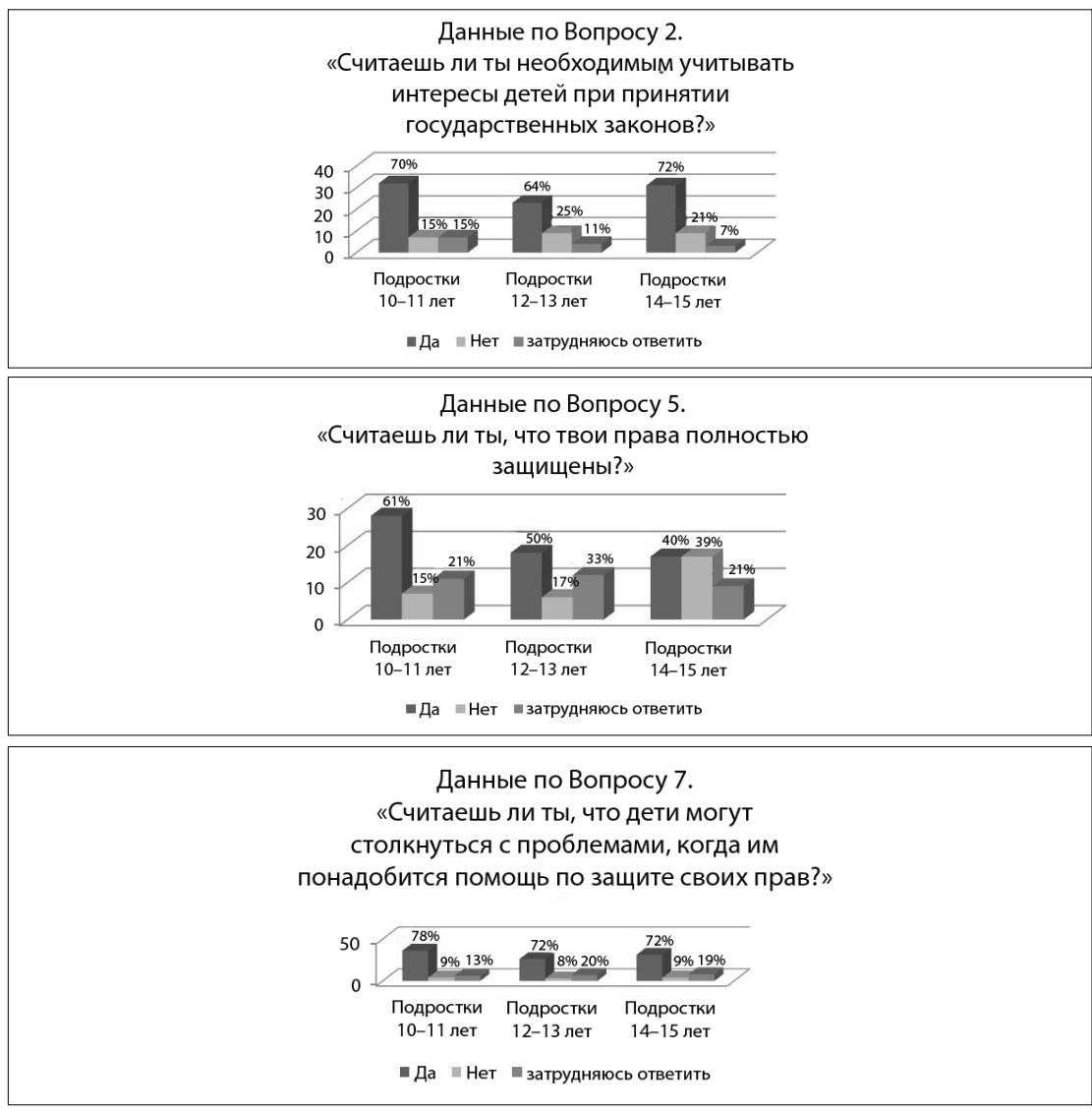

Рисунок 5. Аанные по второму блоку вопросов $(2,5,7)$

Figure 5. Data on the second set of questions $(2,5,7)$

Сравнительный анализ данных представлений подростков по второму блоку вопросов показал, что для более чем 70 \% подростков трех возрастных 
групп представляется необходимым учитывать интересы ребенка при принятии государственных законов; если детям понадобится помощь по защите их прав, они столкнутся с проблемами. 61\% подростков 10-11 лет уверены в защищенности своих прав, в то время как 14-15-летние подростки не уверены в этом (рисунок 5).

Данные по третьему блоку вопросов отражены на рисунке 6.

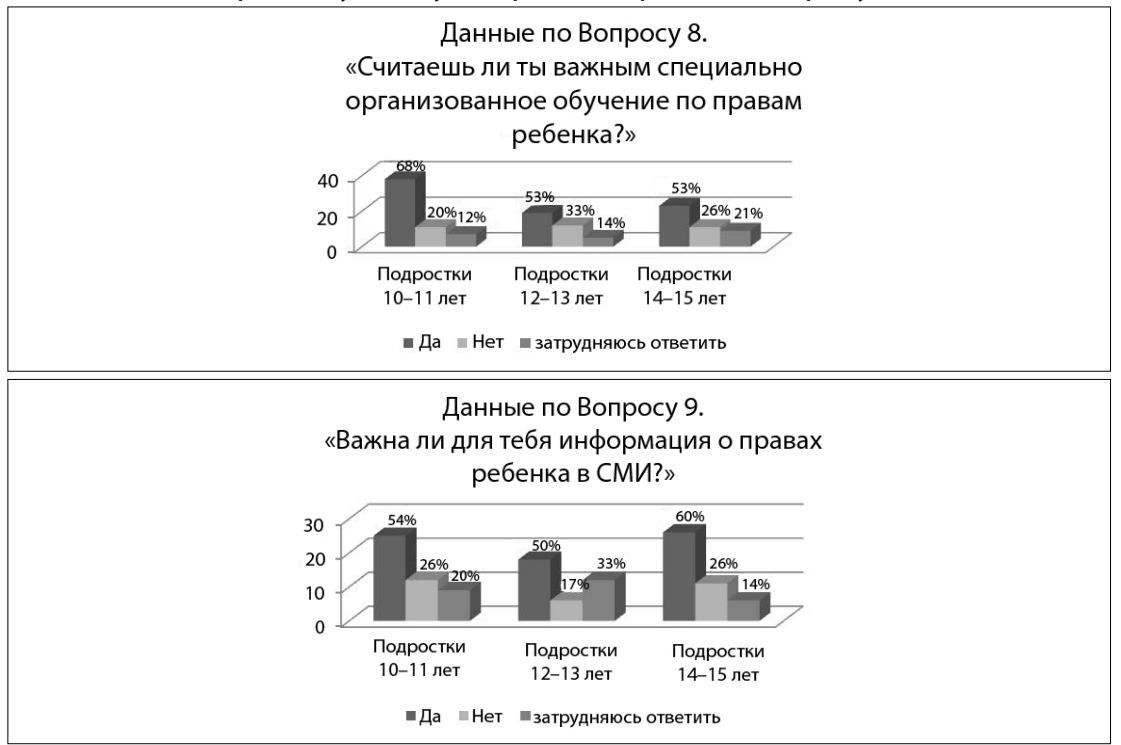

Рисунок 6. Аанные по третьему блоку вопросов $(8,9)$

Figure 6. Data on the third set of questions $(8,9)$

Сравнительный анализ данных представлений подростков по третьему блоку вопросов в трех возрастных группах показал следующие результаты. Для 68\% подростков 10-11 лет в большей степени представляется важным наличие специального обучения по правам ребенка. Для 12-13-летних подростков наличие специального обучения по правам ребенка и информирования о правах ребенка в СМИ представляется важным в равной степени. Для $60 \%$ опрошенных 14-15-летних подростков в большей степени важным представляется наличие информации о правах ребенка в СМИ.

Для определения статистической достоверности различий представлений о правах ребенка подростков 10-11, 12-13, 14-15 лет использован U-критерий Манна - Уитни. Полученные данные свидетельствуют о статистически достоверных различиях в представлениях подростков о правах ребенка 10-11 
и 14-15 лет в ответах на вопросы «Считаешь ли ты, что твои права полностью защищены?» и «Как ты считаешь, допустимо ли ограничение твоих прав?». Статистически значимые различия получены о представлениях подростков 10-11, 12-13, 14-15 лет по Н-критерию Крускала - Уоллиса. Полученные данные свидетельствуют о возрастных различиях в представлениях подростков 10-11, 12-13, 14-15 лет о правах ребенка в ответе на вопрос «Считаешь ли ты, что твои права полностью защищены?». Подростки 14-15 лет более осведомлены о правах ребенка, об их важности и значимости. В отличие от 10-11-летних подростков, 14-15-летние подростки считают, что ограничение их прав недопустимо.

\section{Обсуждение результатов}

Систематизация исследований о правах ребенка и международных проектов по изучению представлений о правах ребенка показала их представленность в работах зарубежных авторов в контексте более широкого круга вопросов изучения детства, детского развития, детского благополучия и образования в области прав человека/ребенка. Качественное своеобразие представленных в международной практике методов исследования прав ребенка связано с соблюдением основных принципов Конвенции о правах ребенка, участием детей в качестве исследователей, разнообразием визуальных, письменных, рисуночных и игровых средств.

В эмпирическом исследовании получены данные о возрастных различиях в представлениях подростков о правах ребенка с использованием адаптированного экспресс-опросника «Представления о правах ребенка», разработанного на основе Флеш-Евробарометра ЕС «Конвенция о правах ребенка» и анкеты ЮНИСЕФ «Детский игровой отчет по правам ребенка». 14-15-летние подростки более осведомлены о правах ребенка, об их важности и значимости. Они также считают, что ограничение их прав недопустимо, и их права недостаточно защищены. Возрастные отличия существуют также в предпочтениях подростков относительно источников получения информации о правах ребенка.

Полученные в исследовании данные могут быть использованы при проектировании программ психологического просвещения и образования подростков в области прав ребенка. Целевая, содержательная и организационная рамки просветительских программ для 10-11 и 12-13-летних подростков могут быть ориентированы на приоритеты специально организованного образования в области прав человека. Учитывая важность наличия информации о правах ребенка для подростков 14-15 лет, могут быть использованы ресурсные возможности интернет-порталов международных и общероссийских организаций по правам ребенка [30]. 


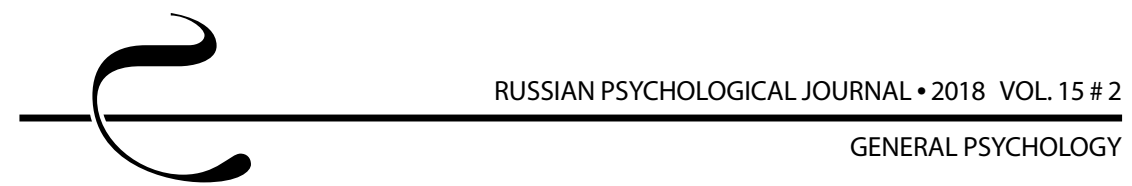

Опыт психологического исследования представлений подростков о правах ребенка показывает перспективность данного направления работы в профессиональной деятельности педагога-психолога и других специалистов, ответственных за образование в области прав человека.

\section{Литература}

1. Мухина В. С. Возрастная психология. Феноменология развития: учебник для студ. высш. учеб. заведений. 15-е издание. М.: Академия, 2015. $656 \mathrm{c.}$

2. Daiute C. The Rights of Children, the Rights of Nations: Developmental Theory and the Politics of Children's Rights // Journal of Social Issues. 2008. Vol. 64, Issue 4. P. 701-723. DOI: 10.1111/j.1540-4560.2008.00585.x

3. TarulliD.\&Skott-MyhreH.The Immanent Rights of the Multitude: An Ontological Framework for Conceptualizing the Issue of Child and Youth Rights // International Journal of Children's Rights. 2006. Vol. 14, Issue 2. P. 187-201.

4. Krappmann L. The weight of the child's view (Article 12 of the Convention on the Rights of the Child) // International Journal of Children's Rights. 2010. Vol. 18, Issue 4. P. 501-513. DOI: 10.1163/157181810X528021

5. Liebel M., Hanson K., Saadi I., Vandenhole W. Children's Rights from Below: Cross-cultural perspectives. Basingstoke: Palgrave Macmillan, 2012. 272 p. DOI: $10.1057 / 9780230361843$

6. Ben-Arieh A. \& Frønes I. Taxonomy for child well-being indicators: A framework for the analysis of the well-being of children // Childhood. 2011. Vol. 18, Issue 4. P. 460-476. DOI: 10.1177/0907568211398159

7. Woodhead M. Child Development and the Development of Childhood // The Palgrave Handbook of Childhood Studies / Qvortrup J. et al. (Eds.). Basingstoke: Palgrave, 2009. P. 46-61.

8. James A. \& Prout A. A new paradigm for the sociology of childhood? Provenance, promise and problems // Constructing and reconstructing childhood: contemporary issues in the sociological study of childhood. 2nd ed. London: Falmer Press, 1997. P. 7-33.

9. Peleg N. Reconceptualising the Child's Right to Development: Children and the Capability Approach // International Journal of Children's Rights. 2013. Vol. 12. URL: https://ssrn.com/abstract=3033458 (Accessed 16.05.2018).

10. Черная A. В. Концепт «детское благополучие» в исследованиях детского развития // Личность в культуре и образовании: психологическое сопровождение, развитие, социализация: сборник научных статей / под общ. ред. А. В. Черной. Ростов н/Д: Изд-во ЮФУ, 2014. С. 80-84.

11. Выготский Л. С. Собрание сочинений в 6 т. Т. 2: Проблемы общей психологии. М.: Педагогика, 1982. 504 с. 
12. Mcloughlin C. S., Hart St. N. Children's rights and school psychology: An introduction to the multiple journal series honoring the 25th anniversary of the United Nations Convention on the Rights of the Child // School Psychology International. 2014. Vol. 35, Issue 1. P. 3-5. DOI: 10.1177/0143034313508876

13. Kosher H. \& Ben-Arieh A. What children think about their rights and their wellbeing: A cross-national comparison // American Journal of Orthopsychiatry. 2017. Vol. 87 (3). P. 256-273. DOI: $10.1037 /$ ort0000222

14. Expert meeting human rights education and fundamental rights awareness for psychologists. Venice, 9-11 October 2016. 22 p. URL: http://human-rights. efpa.eu/information/ (Accessed 17.05.2018).

15. Munford R. \& Sanders J. Interviewing children and their parents // Research Ethics in Aotearoa New Zealand: Concepts, Practice, Critique / M. Tolich (Ed.). New Zealand: Pearson Education New Zealand, 2001. P. 99-111.

16. Nastasi B. K. Empowering child voices through research // The Praeger Handbook of Social Justice and Psychology: Vol. 3. Youth and Disciplines in Psychology / C. Johnson, H. Friedman, J. Diaz, Z. Franco, \& B. Nastasi (Eds.). Santa Barbara, CA: ABC-CLIO, Praeger, 2014. P. 75-90.

17. Backe-Hansen E. Between participation and protection: Involving children in child protection research // Cross-cultural child research: ethical issues / H. Fossheim (Ed.). The Norwegian National Research Ethics Committees, 2013. P. 97-128.

18. Nastasi B. K. Cultural competence for global research and development: Implications for school and educational psychology // International Journal of School \& Educational Psychology. 2017. Vol. 5, Issue 3. P. 207-210. DOI: 10.1080/21683603.2016.1276817

19. Peterson-Badali M., Ruck M. D. Studying Children's Perspectives on SelfDetermination and Nurturance Rights: Issues and Challenges // Journal of Social Issues. 2008. Vol.64, Issue 4. P. 749-769. DOI: 10.1111/j.1540-4560.2008.00587.X

20. A Handbook of Children and Young People's Participation: Perspectives from Theory and Practice / B. Percy-Smith, N. Thomas (Eds.). Abingdon \& New York: Routledge, 2010. 382 p.

21. The National Quality Framework for Early Childhood Education: Research Digest: Standard 1 Rights of the Child. Centre for Early Childhood Development \& Education, 2011. 11 p. URL: http://siolta.ie/media/pdfs/Research\%20Digest\% 20-\%20Rights\%200f\%20the\%20child.pdf (Accessed 22.05.2018).

22. Te One S. Supporting children's participation rights: curriculum and research approaches // Researching Young Children's Perspectives: Debating the Ethics and Dilemmas of Educational Research with Children / D. Harcourt, B. Perry, T. Waller (Eds.). 1st ed. NY: Routledge, 2011. P. 80-85. 
23. Analytical report Flash EB № 235 - The Rights of the Child. European Commission, 2008. 77 p. URL: https://resourcecentre.savethechildren.net/ sites/default/files/documents/3596.pdf (Accessed 22.05.2018).

24. Analytical report Flash EB № 273 - The Rights of the Child. European Commission, 2009. 76 p. URL: https://resourcecentre.savethechildren.net/ sites/default/files/documents/3597.pdf (Accessed 22.05.2018).

25. Children's rights, as they see them / Directorate-General for Justice (European Commission) (Corp. author(s)). Luxembourg: Publications Office of the European Union, 2011. 32 p. DOI: $10.2758 / 58790$

26. Children's Report on Child Rights and Children's Issues. Presented to the United Nations Committee on the Rights of the Child. UNICEF Office for Thailand, 2003. 51 p. URL: https://www.unicef.org/thailand/Child Rightseng full.pdf (Accessed 22.05.2018).

27. Bihar Children Reports on their rights: An alternative report prepared by the children of Bihar on the actual rights granted to them with respect to the rights guaranteed for in UNCRC. Bodhgaya, Gaya, Bihar: Gandhi Peace Foundation Centre, 2008-2009. 15 p.

28. Children and Participation: Research, monitoring and evaluation with children and young people // Kirby P. Involving Young Researchers: How to Enable Young People to Design and Conduct Research. UK: Joseph Rowntree Foundation, 1999. 48 p. URL: https://www.crin.org/en/docs/resources/ publications/hrbap/SCUK participation.pdf (Accessed 22.05.2018).

29. Первин Л., Джон О. Психология личности: Теория и исследования. М.: Аспект Пресс, 2001.607 с.

30. Черная А. В., Гришина Л. Н. Права ребенка в представлениях подростков: опыт психологического исследования и проектирования просветительских программ // Психологическая безопасность личности в поликультурной среде жизнедеятельности: сборник научных трудов по материалам IV-й ежегодной научно-практической конференции преподавателей, студентов и молодых ученых Северо-Кавказского федерального университета. Ставрополь: Изд-во СКФУ, 2016. C. 86-95.

\section{References}

1. Mukhina V.S. Vozrastnaya psikhologiya. Fenomenologiya razvitiya [Developmental psychology: Phenomenology of development]. Moscow, Akademiya Publ., 2015. 656 p.

2. Daiute $C$. The rights of children, the rights of nations: Developmental theory and the politics of children's rights. Journal of Social Issues, 2008, V. 64, no. 4, pp. 701-723. DOI: 10.1111/j.1540-4560.2008.00585.x 
3. Tarulli D., Skott-Myhre H. The immanent rights of the multitude: An ontological framework for conceptualizing the issue of child and youth rights. International Journal of Children's Rights, 2006, V. 14, no. 2, pp. 187-201.

4. Krappmann L. The weight of the child's view (Article 12 of the Convention on the Rights of the Child). International Journal of Children's Rights, 2010, V. 18, no. 4, pp. 501-513. DOI: 10.1163/157181810X528021

5. Liebel M., Hanson K., Saadi I., Vandenhole W. Children's rights from below: Cross-cultural perspectives. Basingstoke, Palgrave Macmillan, 2012. 272 p. DOI: $10.1057 / 9780230361843$

6. Ben-Arieh A., Frønes I. Taxonomy for child well-being indicators: A framework for the analysis of the well-being of children. Childhood, 2011, V. 18, no. 4, pp. 460-476. DOI:

7. Woodhead M. Child development and the development of childhood. In: Qvortrup J. et al. (eds.) The Palgrave handbook of childhood studies. Basingstoke, Palgrave, 2009, pp. 46-61.

8. James A., Prout A. A new paradigm for the sociology of childhood? Provenance, promise and problems. Constructing and reconstructing childhood: contemporary issues in the sociological study of childhood. London, Falmer Press, 1997, pp. 7-33.

9. Peleg N. Reconceptualising the child's right to development: Children and the capability approach. International Journal of Children's Rights, 2013, V. 12. Available at: https://ssrn.com/abstract=3033458 (Accessed 16 May 2018).

10. Chernaya A. V. Children's well-being concept in child development studies. In: Chernaya A. V. (ed.) Lichnost'v kul'ture i obrazovanii: psikhologicheskoe soprovozhdenie, razvitie, sotsializatsiya: sbornik nauchnykh statei [Personality in culture and education: Psychological support, development, and socialization]. Rostov-on-Don, SFU Publ., 2014, pp. 80-84.

11. Vygotskii L. S. Sobranie sochinenii v 6 t. T. 2: Problemy obshchei psikhologii [Collected works in 6 volumes: V. 2. Problems of general psychology]. Moscow, Pedagogika Publ., 1982. 504 p.

12. Mcloughlin C. S., Hart St. N. Children's rights and school psychology: An introduction to the multiple journal series honoring the 25th anniversary of the United Nations Convention on the Rights of the Child. School Psychology International, 2014, V. 35, no. 1, pp. 3-5. DOI: $10.1177 / 0143034313508876$

13. Kosher H. \& Ben-Arieh A. What children think about their rights and their well-being: A cross-national comparison. American Journal of Orthopsychiatry, 2017, V. 87 (3), pp. 256-273. DOI: 10.1037/ort0000222

14. Expert meeting human rights education and fundamental rights awareness for psychologists. Venice, 9-11 October 2016. 22 p. Available at: http://humanrights.efpa.eu/information/ (Accessed 17 May 2018). 
15. Munford R., Sanders J. Interviewing children and their parents. In: M. Tolich (ed.) Research ethics in aotearoa New Zealand: Concepts, practice, critique. New Zealand, Pearson Education New Zealand, 2001, pp. 99-111.

16. Nastasi B. K. Empowering child voices through research. In: C. Johnson, H. Friedman, J. Diaz, Z. Franco, and B. Nastasi (eds.) The Praeger handbook of social justice and psychology: V. 3. Youth and disciplines in psychology. Santa Barbara, CA, ABC-CLIO, Praeger, 2014, pp. 75-90.

17. Backe-Hansen E. Between participation and protection: Involving children in child protection research. In: H. Fossheim (ed.) Cross-cultural child research: ethical issues. The Norwegian National Research Ethics Committees, 2013, pp. 97-128.

18. Nastasi B. K. Cultural competence for global research and development: Implications for school and educational psychology. International Journal of School \& Educational Psychology, 2017, V. 5, no. 3, pp. 207-210. DOI: 10.1080/21683603.2016.1276817

19. Peterson-Badali M., Ruck M. D. Studying children's perspectives on selfdetermination and nurturance rights: issues and challenges. Journal of Social Issues, 2008, V. 64, no. 4, pp. 749-769. DOI:10.1111/j.1540-4560.2008.00587.x

20. Percy-Smith B., Thomas N. (eds.) A handbook of children and young people's participation: Perspectives from theory and practice. Abingdon \& New York, Routledge, 2010. $382 \mathrm{p}$.

21. The National Quality Framework for Early Childhood Education: Research Digest: Standard 1 Rights of the Child. Centre for Early Childhood Development \& Education, 2011.11 p. Available at: http://siolta.ie/media/pdfs/Research\%20 Digest\%20-\%20Rights\%20 of\%20the\%20child.pdf (Accessed 22 May 2018).

22. Te One S. Supporting children's participation rights: curriculum and research approaches. In: D. Harcourt, B. Perry, T. Waller (eds.) Researching young children's perspectives: Debating the ethics and dilemmas of educational research with children. NY, Routledge, 2011, pp. 80-85.

23. Analytical report Flash EB № 235 - The Rights of the Child. European Commission, 2008. 77 p. Available at: https://resourcecentre.savethechildren.net/sites/ default/files/documents/3596.pdf (Accessed 22 May 2018).

24. Analytical report Flash EB № 273-The Rights of the Child. European Commission, 2009. 76 p. Available at: https://resourcecentre.savethechildren.net/sites/ default/files/documents/3597.pdf (Accessed 22 May 2018).

25. Children's rights, as they see them. In: Corp. author(s). Directorate-General for Justice (European Commission). Luxembourg, Publications Office of the European Union, 2011. 32 p. DOI: $10.2758 / 58790$

26. Children's Report on Child Rights and Children's Issues. Presented to the United Nations Committee on the Rights of the Child. UNICEF Office for Thailand, 2003. 
51 p. Available at: https://www.unicef.org/thailand/Child Rights-eng full. pdf (Accessed 22 May 2018).

27. Bihar children reports on their rights: An alternative report prepared by the children of Bihar on the actual rights granted to them with respect to the rights guaranteed for in UNCRC. Bodhgaya, Gaya, Bihar, Gandhi Peace Foundation Centre, 2008-2009. 15 p.

28. Children and Participation: Research, monitoring and evaluation with children and young people. In: Kirby P. Involving Young Researchers: How to Enable Young People to Design and Conduct Research. UK, Joseph Rowntree Foundation, 1999. 48 p. Available at: https://www.crin.org/en/docs/ resources/publications/hrbap/SCUK participation.pdf (Accessed 22.05.2018).

29. Pervin L., John O. Psikhologiya lichnosti: Teoriya i issledovaniya [Personality psychology: theory and research]. Moscow, Aspekt Press Publ., 2001.607 p.

30. Chernaya A.V., Grishina L. N. Prava rebenka v predstavleniyakh podrostkov: opyt psikhologicheskogo issledovaniya i proektirovaniya prosvetitel'skikh programm [Adolescents' notions about children's rights: The experience of psychological research and developing educational programs]. Sbornik nauchnykh trudov po materialam IV-i ezhegodnoi nauchno-prakticheskoi konferentsii prepodavatelei, studentov i molodykh uchenykh SeveroKavkazskogo federal'nogo universiteta "Psikhologicheskaya bezopasnost' lichnosti v polikul'turnoi srede zhiznedeyatel'nosti" [Proc. The 4th Annual Theoretical and Practical Conference of Teachers, Students and Young Scientists of North-Caucasus Federal University "Psychological safety of the individual in a multicultural environment"]. Stavropol, North-Caucasus Federal University Publ., 2016, pp. 86-95. 